\title{
Health needs, health seeking pathways, and drivers of health seeking behaviors of female garment factory workers in Cambodia: Findings from a qualitative study in Phnom Penh and Kandal provinces
}

Population Council

The Evidence Project

Follow this and additional works at: https://knowledgecommons.popcouncil.org/departments_sbsr-rh

Part of the Demography, Population, and Ecology Commons, Family, Life Course, and Society Commons, International and Comparative Labor Relations Commons, International Public Health Commons, and the Women's Health Commons How does access to this work benefit you? Let us know!

\section{Recommended Citation}

"Health needs, health seeking pathways, and drivers of health seeking behaviors of female garment factory workers in Cambodia: Findings from a qualitative study in Phnom Penh and Kandal provinces," Policy brief. Phnom Penh: Population Council, The Evidence Project, 2017. 


\section{Introduction}

The garment sector is a main driver of the Cambodian economy, accounting for over $80 \%$ of national export income. Female workers, most of whom are of reproductive age, are essential to the sector's productivity, comprising $85 \%$ of the 700,000 workers in the Cambodian garment sector and a significant proportion of women working in the formal sector in Cambodia overall. Although female garment factory workers (GFW) are recognized as vulnerable to poor health conditions and having inadequate access to health care, understanding of their particular health needs, especially in reproductive health (RH) and family planning (FP), is limited by weak and anecdotal evidence. Existing information on GFWs' barriers to health services has generally come from project implementation documents or general baseline studies of these projects, rather than independent, rigorous studies that specifically examine the health needs and health seeking behaviors of workers. Since previous studies did not include specific indicators related to workers' health needs and health seeking behaviors, they cannot offer a complete picture of these important issues.

To fill this critical knowledge gap, in partnership with the National Institute of Public Health (NIPH), the Evidence Project/Population Council conducted a formative qualitative study under the USAID-funded WorkerHealth project to improve the understanding of health needs, health seeking pathways, and drivers of health seeking behaviors of female GFWs in Cambodia (see Box 1). Though the study focused broadly on health needs, the findings emphasize workers' concerns regarding sexual and reproductive health care and FP services. The study was conducted between April and May 2016, and used a rigorous qualitative research methodology to capture more fully the individual, social, and institutional dynamics that shape health seeking behaviors of workers. Furthermore, this research study offers the first illustrative mapping of the health seeking pathways of female GFWs, which provides a richer understanding of workers' perceptions of health care quality and of the values, beliefs, and socio-economic conditions that shape decision-making on how and where to seek healthcare in communities.

Understanding the complex dynamics of healthcare decision-making, including health seeking behaviors, is necessary to design and implement effective and thoughtful programs that enable garment workers to adequately and effectively access required health services. There are increasing efforts by various stakeholders, including the government, donors, nongovernmental organizations (NGOs), and industry, to improve worker well-being in Cambodia's garment
BOX 1

\section{WORKERHEALTH INTERVENTION}

WorkerHealth project is an initiative of USAID Cambodia which aims at improving the health and wellbeing of garment sector workers. The project brings together distinct areas of policy change, service delivery and research and with a strong focus on sustainability. WorkerHealth works to build and improve upon the preexisting structures in Cambodia, and engages participation of different stakeholders, including relevant government bodies, private sector, and different NGOs. Through combining rigorous research methods and service delivery mechanisms, WorkerHealth brings together the research emphasis of Population Council and the health delivery focus of Marie Stopes International Cambodia.

sector, and the findings from this study serve as an informative resource to better understand health seeking behaviors of garment factory workers in the current health programming and policy landscape in Cambodia.

This brief complements two other WorkerHealth project review documents: (1) "Garment Sector Health Interventions in Cambodia: A Comprehensive Review" (Heng and Bajracharya 2017), which provides a foundational and comprehensive background review of previous garment sector health interventions, including best practices and gaps in programming and evaluation; and (2) "Workplace Health and the Garment Sector in Cambodia" (Yat, Rodehau, and Wofford 2017), which organizes and analyzes the dynamics of different stakeholders, and their direct and indirect connections to garment worker well-being, health, and the policy landscape.

\section{Research Questions}

To achieve its stated objectives, the study addressed the following key research questions:

1. What are female GFWs' major health issues?

2. How do female GFWs access health services for general illnesses and for RH and FP?

3. What challenges do female GFWs face in seeking general health care and RH and FP services?

4. What factors facilitate access to and utilization of health services for general illnesses and RH and FP?

5. What are the priority health needs and desired health support for female GFWs? 


\section{Methods}

The study took place in four factories participating in the WorkerHealth project: three in Phnom Penh and one in Kandal province. Understanding that the garment factory workforce is heterogeneous, with diverse health needs, the study purposively sampled female GFWs ages $18-45$, with the samples further divided by marital status, residency, and means of transportation to work.

Data were collected using three qualitative methodologies: (1) 22 in-depth interviews (IDIs) with female GFWs; (2) eight focus group discussions (FGDs) with female GFWs; and (3) 27 key informant interviews (KIIs) with various stakeholders, including management representatives of the factories, line/group supervisors on factory floors, worker representatives, infirmary staff, pharmacy owners, cabinet staff, medical staff of private clinics that provide health services to garment workers, managers and staff of NGOs working to improve the health and well-being of female GFWs, and truck drivers who help workers commute to and from the factories . During each IDI and FGD, a health seeking pathway map was constructed by interviewers and workers together, using social mapping to illustrate how and where the worker respondents and garment workers in general sought general and RH and FP services (see Box 2 for definitions of health care facilities).

\section{What are the Major Health Issues of Female Workers?}

Female GFWs described their major health problems in three categories: (1) common illnesses, such as cold, fever, flu, headache, dizziness, fatigue, and fainting (2)

RH and FP issues, such as contraception, irregular menstruation, abnormal vaginal discharge, vaginal bleeding, miscarriage, and hemorrhage; and (3) other, less acute conditions relating to the digestive tract, urinary tract infections, and hemorrhoids. Factory managers, infirmary staff, private health providers, and staff of NGOs implementing garment sector health interventions reported similar health issues among female GFWs.

\section{“...Yes, a lot of woman-related illnesses [reproductive issues], stomachache, typhoid, hemorrhoids, pain before menstruation, and vaginal discharge..."}

$$
\text { -FGD, Married, Factory } 3
$$

"T knew that workers liked using contraceptive pills...I also knew that workers also had the issues of abnormal discharge or irregular menstrual period..."

$$
\text { -KII, Manager, Factory } 1
$$

\section{HEALTH CARE FACILITIES DEFINITIONS}

Factory infirmary: Factories are required to establish an infirmary on the premises to provide basic healthcare and first aid services to their workers.

Pharmacy: Drug stores generally run by registered pharmacists; nonprescription drugs are also sold at pharmacies.

Cabinet: Small private clinics usually run as family businesses; cabinets are not always licensed, and services vary, depending on the capacity of providers.

Private clinic: These have at least 10 beds and offer outpatient and inpatient services, various medical specialties, laboratory, radiology, and pharmacy services.

Health center: First-level facilities in the Cambodian public health system, providing services such as general health consultation, STI/AIDS prevention and treatment, minor surgery, pre-natal care, family planning, normal (non-Caesarean) labor and delivery services, and post-partum care.

Public hospital: This category includes national hospitals (located in Phnom Penh) and referral hospitals (located in provinces), providing general and specialist health services.

"There is also a need for contraception, but I don't provide the services, but only counseling when requested. I often encourage workers to find the services outside..." -KII, Infirmary Staff, Factory 2

While the workers, managers, and service providers all agreed on what the major health concerns for workers were, they held different views on the causes of these ailments. For GFWs, health problems were inextricably tied to their factory work experience, unhealthy lifestyles, and reproductive health issues (e.g. fatigue or fainting due to side effects from FP methods or to severe pain during menstruation). Infirmary staff and external health care providers named specific work hazards such as chemical substances in the fabric and slippery floors, work accidents, and insufficient food intake as the causes of reported health issues. On the other hand, factory management representatives believed that these health problems were due to causes outside of work, specifically the workers' unhealthy habits and lifestyles, and listed tiredness from not sleeping during off 
hours, flu or seasonal sickness, and unhygienic living conditions as causes of worker health issues.

"... problem of irregular menstruation. When it is irregular like this, [I had] terrible abdominal pain and sometimes passed out."

FGD, Single, Factory 1

"In factory, chemical substance could be used and so it is unavoidable that it could affect the health of workers, for example, causing fainting..."

$$
\text { -KII, Infirmary Staff, Factory } 2
$$

"It could also be the cause of lack of bygiene in their food consumption. It is a combination of many factors, I think..."

-KII, Manager, Factory 3

\section{How do Workers Seek Health Care Services? \\ General Illnesses}

The health seeking behaviors of female factory workers varied by the type and perceived severity of their illness (see Figure 1). The main factors shaping how workers sought care were cost and proximity of the health services; other considerations included quality of care, availability of specialty care, and ethics and kindness of providers.

For general illnesses, workers tended to categorize their conditions into mild, prolonged, severe, and lifethreatening. For conditions they felt to be mild, for example flu or headache, workers sought remedy on
BOX 3

\section{COIN RUBBING}

The Southeast Asian folk therapy practice of rubbing the edge of a coin across warm, oiled skin, derived from the Chinese practice for treating migraines, fever, and other conditions.

Source: http://medical-dictionary.thefreedictionary.com/Coin+rubbing; Last access: February 28, 2017.

their own by going to a nearby pharmacy when they were sick outside of working hours or an infirmary during working hours. A traditional healing practice of 'coin rubbing' with Tiger Balm pain-relieving ointment was still very popular among workers to treat migraines or fever (see Box 3). During working hours, coin rubbing was performed inside factory infirmaries, which offered private space. Sick female workers often requested and received permission from supervisors for female co-workers to assist with coin rubbing, infirmary staff were focused on other sick staff seeking care at the infirmary.

Workers showed different behaviors in addressing prolonged or severe general health problems. For prolonged or severe illnesses that prevent GFWs from reporting to work and for which oral medicines may not be effective, e.g. severe flu or diarrhea, workers would typically seek care at higher level facilities, such as nearby cabinets and private clinics capable of delivering medication intravenously (IV) (cabinets and

FIGURE 1. SYNTHESIZED HEALTH SEEKING PATHWAYS FOR GENERAL ILLNESSES AMONG FEMALE GFWS

PEOPLE CONSULTED

PLACE OF DEPARTURE
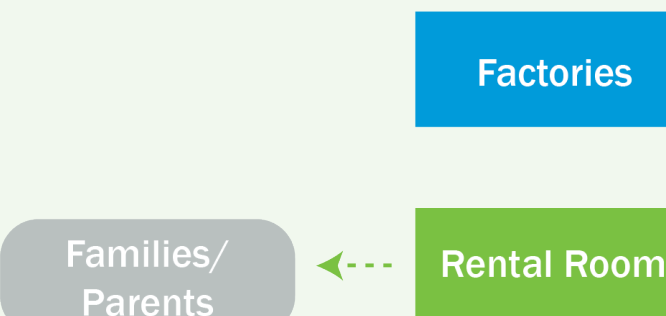
Parents

\section{Rental Rooms}

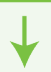

Hometown

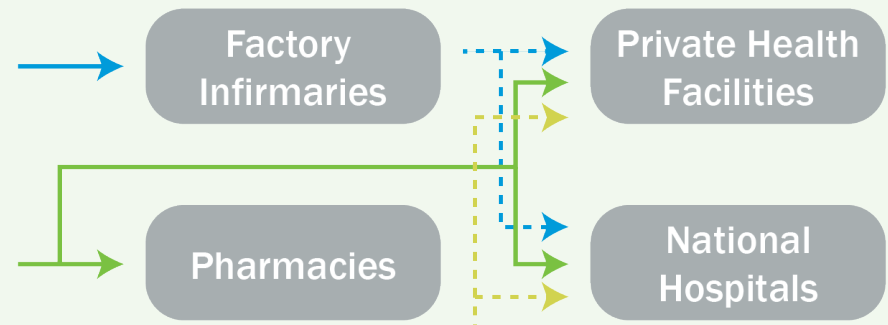




\section{NATIONAL SOCIAL SECURITY} FUND (NSSF)

NSSF has two schemes: 1) work injury and 2) health insurance. The work injury scheme was started in 2008 , and the premium is fully paid by factory management. The health insurance scheme was started in May 2016 and is being piloted. The cost of the health insurance scheme premium is equally shared by factory management and workers. The NSSF work injury scheme established networks of care for events and occupational injuries that occur during working hours. The NSSF health insurance scheme builds on these existing networks of providers to also offer healthcare services to workers.

private clinics are categorized as private health facilities in the health seeking pathway maps). For severe sicknesses that may require specialized care, such as urinary tract infections and pneumonia, workers went to private clinics and public hospitals with specialty services. Workers with severe conditions identified cost as a secondary consideration to quality of care. Single, unmarried workers tended to return to their hometowns in rural provinces, where they could receive support from their families when the treatment and care, for example for typhoid, required a long period of time.

Life-threatening conditions that occur while at the factory and work-related accidents are covered under the National Social Security Fund (NSSF), so workers typically are required to be referred or transferred through the factory infirmary to a public hospital or private facilities contracted with the NSSF work injury scheme for formal sector employees. A broader national health insurance scheme for formal sector employees under the NSSF has also recently been put in place (see Box 4).

\section{RH and FP Services}

Garment workers seek reproductive health and family planning services from a variety of places, depending on their needs (see Figure 2).

\section{Family planning}

Workers reported using a wide range of FP methods, including modern methods such as pills, injectables, implants, and IUDs, and male condoms. Withdrawal, considered a traditional method, was also frequently mentioned as a preferred method. Partners, relatives, and friends were the most influential people in determining what methods the factory workers used.

"I control birth through the natural method. My busband participated in doing it.... Elders told me I should use natural methods"

-IDI3, Married, Factory 4

"I wanted to use the implant or IUD as advised by health providers, but my husband said I should not..."

-IDI2, Married, Factory 1

"The large proportion of garment workers decided to choose family planning methods based on their friends' advice."

- KII, NGO 1

\section{FIGURE 2. SYNTHESIZED HEALTH SEEKING PATHWAYS FOR FP AND RH AMONG FEMALE GFWS}

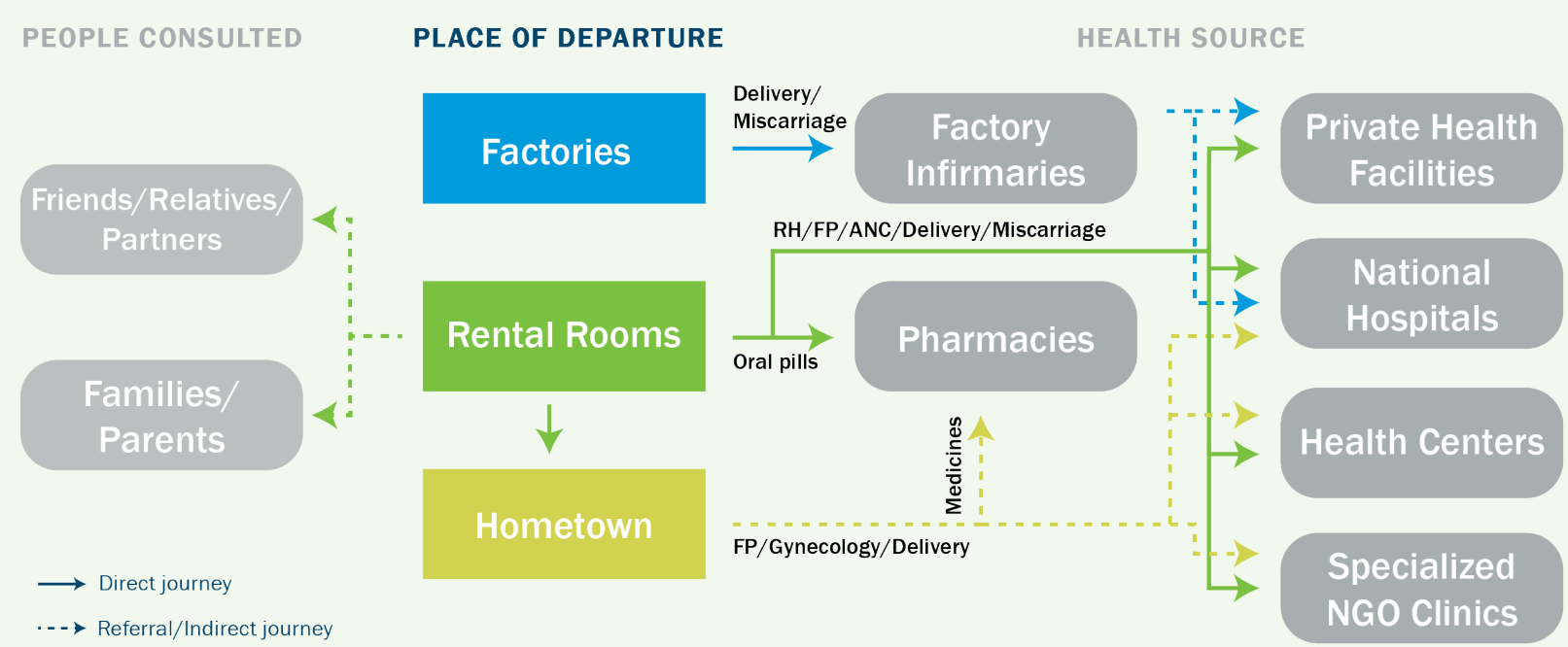


Oral pills were the most commonly used family planning method among GFWs. Workers reported that they chose this method based on its low cost, easy availability, ability to switch easily, and convenience of getting counseling on its use. Most GFWs who used oral pills obtained them from pharmacies or drug stores close to their homes or factories. When workers experienced a side effect of the oral pill, they would change from one brand of the pill to another or switch to natural methods, but less frequently to other modern methods.

\section{"I chose to use birth control pills because I could stop using it anytime I wanted to have a baby. If I use implant or IUD, I need to go to providers to ask them to remove it first."}

-IDI3, Married, Factory 4

Injections were the second most common method after oral pills, while IUDs and implants were less reported among our sample of workers. However, most workers avoided long-acting contraceptives due to misconceptions about those methods, ranging from prohibitions on specific activities when using implants (e.g. heavy lifting) to dizziness from amenorrhea when using injectables. Furthermore, workers preferred pills because they enjoyed the autonomy of starting or stopping pills at will.

\section{"I want to use implant or IUD, but I heard about} their side effects, so I'm afraid of it. People told me that when we use implant, we couldn't carry heavy objects"

$$
\text { -IDI3, Married, Factory } 2
$$

"Most of workers preferred taking pills than injection or other methods. [Why?] From my experience, when I used injection, I did not have period. Having no period, I often feel dizzy..."

\section{-FGD, Married, Factory 4}

Women were likely to go to an NGO clinic (e.g. Reproductive Health Association of Cambodia (RHAC) or Marie Stopes) or health center if they wanted to get an implant or an IUD. This was partly because these methods were not available at pharmacies or drug stores, but mainly because workers perceived providers at these specialized facilities to be more skilled in delivering these services.

Traditional methods were also a popular FP method. For some workers, withdrawal was their primary method, while others switched to withdrawal after experiencing side effects on modern methods. The use of male condoms was hardly mentioned by GFWs in the IDIs or FGDs.

\section{Antenatal care}

Workers reported seeking antenatal care (ANC) in health centers, private clinics, and RHAC clinics. Since workers were provided only half-day leave from work to get an ANC check-up, the main considerations when choosing an ANC provider were related to distance and waiting hours at the health facility, followed by capacity of the facility to provide this service and costs. Workers usually chose between a health center and an RHAC clinic, depending on the proximity of the facilities. However, workers opted for private clinics when they wanted a higherlevel ANC check-up that required specific equipment, for example ultrasound machines. RHAC clinics were sometimes preferred, regardless of the distance, when they implemented free RH voucher programs.

"Oh, I went to have an ultrasound at Somphob Panha
and Somphob Phally clinics in Takhmao town to find
out the condition of my fetus. Besides that, I often went
to Svay Rolom Health Center."

-IDI3, Married, Factory 4

\section{Delivery practices}

Where workers sought delivery care depended on whether a worker went into labor during working hours, their perception of quality of care in different locations, and whether the worker returned home to their province to deliver with family support. The experiences and advice of family members and friends also influenced women's decisions when choosing a provider. If women were working in the factory when labor started, they were often sent to private clinics or public hospitals that were affiliated with NSSF. If they went into labor at home, most workers chose to deliver in private clinics, health centers, or NGO clinics. Women opted for private clinics based on perceived higher quality of care, distance, friendliness, and quality of care from midwives. Some workers returned to their home province to deliver at public facilities, as they would receive support from families during and after delivery.

"I delivered my child at a private clinic. I also wanted to go to health center, but I had labor at night and the bealth center was far from my place, so I decided to go to the clinic...It was also easy as they provided a good care to me."

-IDI3, Married, Factory 4

"I delivered my child at Chantea Vuth clinic. My aunt used to deliver her child at that clinic and she said the service was good and the midwives also used good words, so she recommended me to go to the clinic."

-IDI2, Married, Factory 3 


\section{Miscarriage and hemorrhage}

Workers who were at home when a miscarriage began would go to a health center to receive treatment. If the miscarriage occurred at the factory, workers would be referred to a close-by private clinic affiliated with the NSSF. In some cases, workers would also return home to receive post-miscarriage care and emotional support from their families.

\section{Gynecological care}

For other gynecological problems that workers deemed severe enough to warrant treatment, such as abnormal vaginal discharge or infection, GFWs often bypassed workplace infirmaries, probably due to reasons of privacy, and went directly to external providers. Workers often opted for specialized NGO clinics, namely RHAC and Marie Stopes, based on recommendations from their friends.

"Never, mostly because we are shy. If cold, headache, or cough, we came to get medicine from factory infirmary. [Other workers said] they were lasy to go to the infirmary [for RH issues]. There is one male and one female staff at the infirmary, so outside is more convenient."

$$
\text { -FGD, Single, Factory } 3
$$

"We went to the near-by pharmacies first. If still not cured, we went back to private clinics at home. For me, I went to a RHAC clinic at my hometown for severe reproductive bealth issues. Actually bealth center also has that services, but my relatives and I have a habit of going to RHAC clinic in our bometown. For RHAC clinics in Phnom Penh, we don't know any health staff there. In our hometown, we know each other."

-FGD, Single, Factory 3
What are the Barriers and Facilitating Factors for GFWs to Access and Use Healthcare Services?

Workers' health seeking behaviors are influenced by unique barriers and facilitating factors at individual, factory, and healthcare system levels.

\section{At the Individual Level}

\section{Facilitating factors}

Support from family and friends. Workers identified partners, families, and friends as an important source of financial and moral support, especially in times of emergency. Parents were always the key persons that workers turned to during severe illnesses.

Knowledge of health care and services among older women. Workers, both married and single, who participated in behavior change communication events organized by NGOs demonstrated better understanding of how to navigate health care services. Older workers who had experienced various health issues and problems were also often a source of information for younger workers.

\section{Barriers}

Limited income. Respondents identified cost as a key constraint for workers seeking health services. Workers' salaries were not enough to cover health treatment, as a significant portion was spent on remittances to their home provinces and on living costs. Respondents noted that workers sometimes borrowed money from family or friends to pay the cost of treatment. When workers

\section{FIGURE 3. FACILITATORS AND BARRIERS TO WORKERS' HEALTH SEEKING BEHAVIORS}

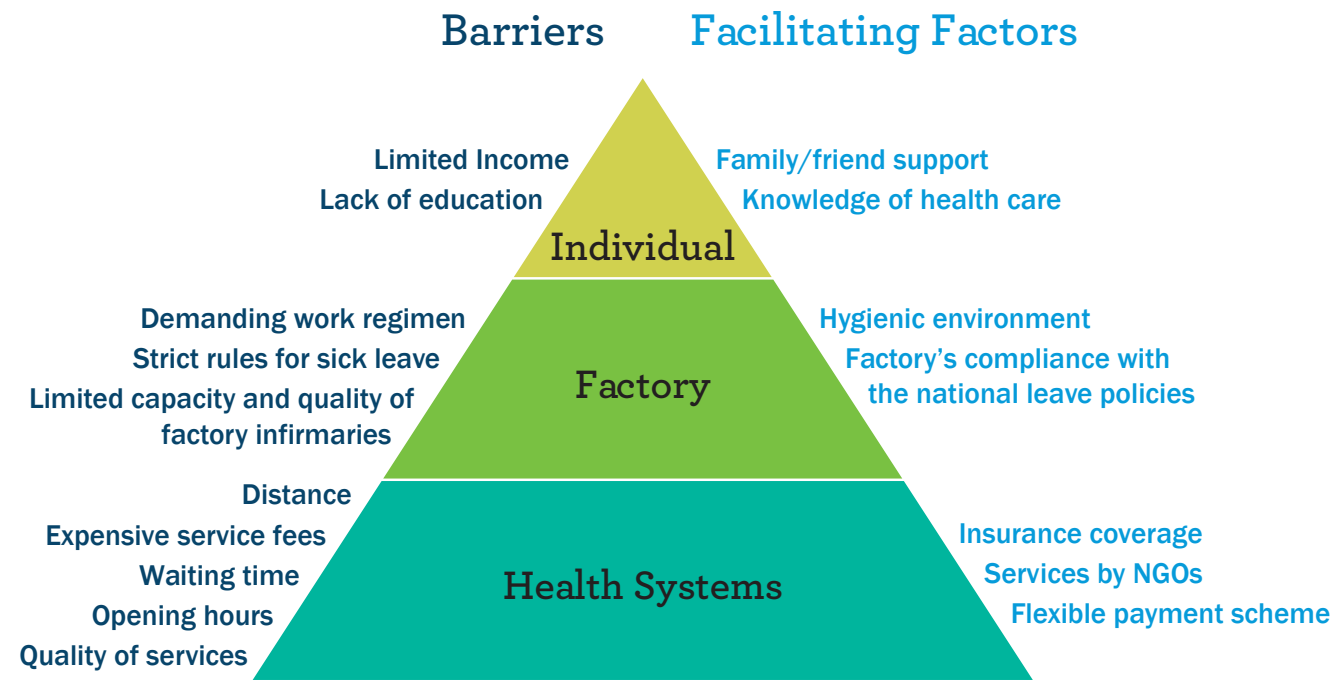


care, including RH and FP. To take sick leave, workers reported that they had to provide notification one day in advance, as well as documentation from approved providers verifying medical reasons for the leave. Taking leave without meeting these requirements would result in salary deductions. Managers reported that this requirement was necessary, as some workers lie about illness or falsify doctor's notes. Workers also reported experiencing pressure from supervisors, especially during demanding production times and the high season, making it challenging to ask supervisors for sick leave. For this reason, workers very often chose to take annual leave instead of sick leave when, for example, they had severe menstrual pain.

\section{"I had to go to see doctor] on Sunday. I dared not ask for sick leave [on working days]. I was afraid they scolded me..."}

$$
\text { -FGD, Single, Factory } 1
$$

Limited capacity and quality of factory infirmary. While infirmaries are the most accessible providers, with free services for GFW, they were reported to have only limited medical supplies, weak capacity for consultation or treatment, and poor attitudes, forcing workers to seek external health services. In addition, some workers voiced concerns regarding trust of infirmary staff, and expressed discomfort with the requirement to obtain their supervisor's authorization prior to accessing care and medication at the infirmary.

"They [infirmary staff] did not ask/ consult anything much. They just gave us medicines. The same medicines for everyone whether headache or abdominal pain. Sometimes the medicines worked, but sometimes not and we had to buy additional medicines from the nearby pharmacies. Sometimes, we went [to the infirmary] for 10 times but did not get any medicines... Without signature from the supervisor, [the infirmary staff] would not give us medicines... Nurses used bad words and did not act like a nurse...they did not make us feel warm. They brought their kids [to the infirmary], so we did not have time to talk with them..."

$$
\text { -FGD, Married, Factory } 2
$$

\section{At the Health Systems Level}

\section{Facilitating factors}

Insurance coverage. Costs associated with work injuries or health problems that occurred during working hours were covered by the NSSF work injury scheme. The government's expansion of NSSF to provide health insurance through co-payments and expanded coverage of comprehensive services at contracted providers is a very positive development. However, many workers in the study were not aware of either the NSSF injury scheme or the expanded health insurance scheme. For poor workers in Kandal province, their healthcare expenditures were further minimized by the implementation of the Health Equity Fund program, which is a national social health protection program for the population; workers in Phnom Penh were less likely to be eligible to use the scheme due to their migration to Phnom Penh.

Services by NGOs. Key implementing NGOs that workers most often mentioned included RHAC, Marie Stopes, and CARE. While these three NGOs all focused on health education for workers, RHAC and Marie Stopes also delivered health services, particularly for $\mathrm{RH}$ and FP issues. RHAC was reported to have extended their clinic operating days to seven days a week to offer weekend hours for GFWs; RHAC also distributed $\mathrm{RH}$ vouchers to workers.

Flexible payment scheme. Some external providers, especially in the provinces, allowed workers to defer treatment cost and pay later.

$$
\begin{aligned}
& \text { "At hometown, we don't need to pay when getting the } \\
& \text { treatment. We can wait until we get our salary to pay. } \\
& \text { Here in Phnom Penh, our money would run out with } \\
& \text { just an IV treatment." }
\end{aligned}
$$$$
\text { -FGD, Single, Factory } 3
$$

\section{Barriers}

Distance of health facilities. The proximity of health providers to GFWs' residences or factories was an important consideration, as transportation to and from the clinic added to the cost and time to seek health care. Thus, workers tended to choose nearby pharmacies and cabinets over health centers and NGO clinics, which were located farther away and involved longer traveling time. Although workers in Kandal province noted the convenience and reasonable price of local transportation in the area, they still preferred seeking healthcare services around their factories due to time constraints. However, some workers were wary of seeking care at factory infirmaries despite the convenient location because they felt the infirmaries' proximity and ties to the workplace could risk confidentiality.

High service fees. The high service fees of higherlevel private clinics and public hospitals led workers to choose care at small, near-by pharmacies and cabinets.

$$
\begin{aligned}
& \text { "Samphob A and Samphob B [private clinics] } \\
& \text { charged up to } \$ 200-S 300 \text { for normal delivery and } \\
& \$ 700-\$ 800 \text { for C-section. Where could we get the }
\end{aligned}
$$




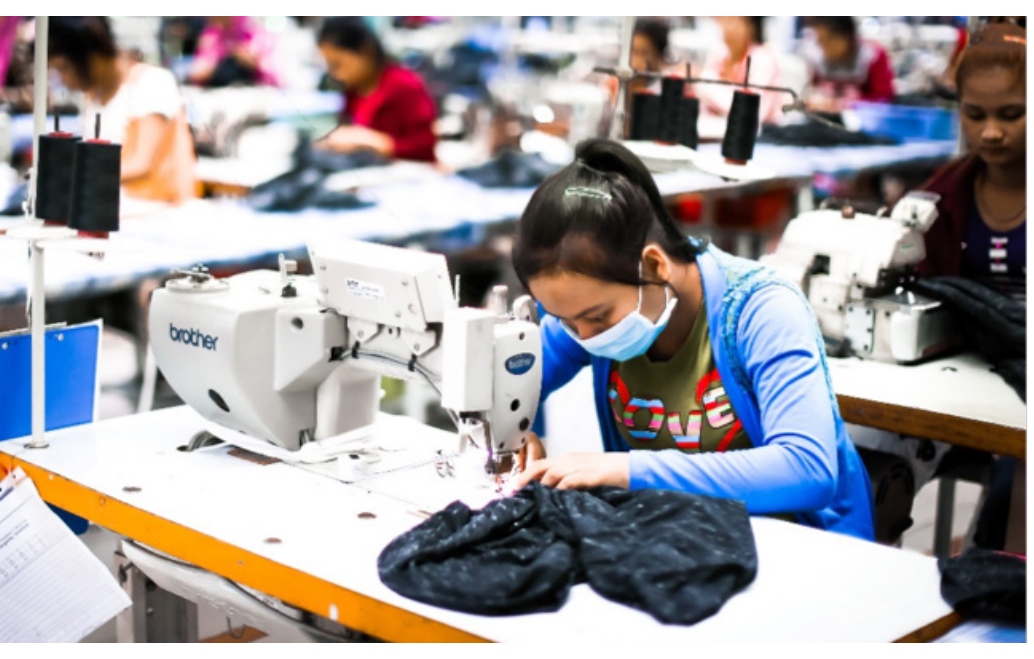

money from? So, only go to Chhey Chbumnas hospital and health center. For general health issues, some people went to bealth centers to get medicines. It cost only 3,000-4,00Riel. [At private clinics] getting one IV with a few injections and oral medicines for three days may cost up to 50,000Riel."

\section{-FGD, Married, Factory 2}

Waiting time. Workers preferred quick services, given inflexible working hours and difficulties asking permission for sick leave. For problems perceived as mild, pharmacies and cabinets were most preferred, while for more severe conditions, private providers and NGO clinics were preferred over public facilities because of perceived long waiting times at public facilities.

Limited quality of care. Workers and clinic-based service providers reported that the quality of services from external health providers could be improved. Pharmacies and cabinets, which workers often used for primary care, offered little counseling or referral services, while health staff at public facilities were sometimes reported as not being client-friendly.

Opening hours. Operating hours of public health facilities were not compatible with GFWs' work schedules, forcing workers to seek healthcare at private facilities if they needed care on weekends.

\section{What are the Priority Health Needs and Desired Health Support for Female GFWs?}

All respondents agreed that $\mathrm{RH}$ and FP is the main health support needed by female garment factory workers, although for different reasons. While practicing a healthy lifestyle can be a preventive measure for common health problems and less acute illnesses, workers believed clinical/medical expertise was needed to treat reproductive issues. Managers and infirmary staff emphasized the importance of $\mathrm{RH}$ and FP for workers' productivity, since the majority of workers are women. External health providers also felt that workers' RH should be a priority, and further recommended providing information on specific topics such as contraception, abnormal discharge, and miscarriage.

"If you are allowed to choose 3 most priority health
needs or topics to support your workers, what do you
choose?] I think general health isn't as important as
the reproductive health and family planning... This
was based on the statistics given by infirmary staff
in this factory that reproductive health is the most
frequent issues in this factory..."

-KII, Manager, Factory 3

"I think if there are reproductive bealth and family planning services, they will be very useful for both married and single workers. Such services are relevant to the productivity of workers because they received good services, they will have good health and don't need to take leave often. We used to think about it as well..."

-KII, Manager, Factory 1

Respondents had different opinions on the effectiveness of past interventions in addressing workers' RH and FP issues. A range of intervention activities were mentioned, including knowledge building and awareness raising, reducing financial barriers to accessing services, promoting use of long-acting methods for family planning, and improving the quality of care. Staff at implementing organizations interviewed as part of the study identified NGO partnerships and involvement of governmental stakeholders as strengths of their intervention implementation. They also noted, however, that past projects were hindered by worker turnover, factory management concern about worker productivity, short project lifespan, and poor choice of intervention approaches. See Heng and Bajracharya (2017) for a detailed analysis of past interventions.

Particularly for service delivery, respondents preferred different approaches to address workers' RH and FP needs. Some workers wanted the services available at factory infirmaries, as they are close and convenient, while others wanted the services outside of but near the factories, to maintain confidentiality as well as geographical proximity. Managers and NGOs also felt that providing RH and FP services close to workers, either at the infirmaries or outside the factories, would reduce barriers of cost and distance and increase workers' uptake of RH and FP services. Many NGO staff also voiced the importance of having $\mathrm{RH}$ and FP services within easy access for workers and having external health providers who treat garment workers with honesty, transparency, quality, and respect. 


\section{Recommendations}

Based on the research findings, several key actions to improve worker health were identified.

\section{Focus on RH and FP issues}

In addition to being one of the major health issues that workers faced and (as perceived by some respondents) a cause of other health problems, such as fatigue and fainting, all respondents agreed that RH and FP should be prioritized by relevant stakeholders working to improve worker health, including government bodies, donors, implementing NGOs, and brands.

\section{Strengthen the capacity and services of factory infirmaries}

A recurring theme was the potential for infirmaries to serve a greater role providing quality health services for workers. Infirmaries are strategically located and costfree, which offer advantages for providing workers with basic health services or counseling for RH and FP, as well as strengthened referral for complex services, all of which can lead to meaningful impacts for the factory workers.

\section{Enhance capacity of external health service providers close to workers}

While work-related injuries or accidents were handled by NSSF-contracted private and public facilities, workers had more choice when it came to RH and FP service providers. If their condition wasn't severe, workers were less likely to seek health services because of perceived poor quality of near-by providers, distance to trusted facilities, cost of services, and time constraints. Building the capacity of external providers close to worker residences or factories, such as small private clinics, cabinets, or pharmacies/drug stores to provide high quality counseling, treatment, and referral could be an effective strategy to improve workers' use of health services.

\section{Promote cooperation and coordination among implementing organizations}

Staff from implementing organizations who participated in this study noted that collaboration among key implementing organizations was a key to their projects' success. However, this practice has only recently gained traction among implementers (see Heng and Bajracharya 2017). Effective collaboration or coordination among NGOs with similar goals could reduce redundancy, enhance intervention effectiveness based on shared lessons learned of the collaborating partners, and expand the scope of the project to maximize the impact. Thus, collaborations could be key for generating support and cooperation from factory management, by addressing their concerns about the inefficiencies of fragmented and uncoordinated factory interventions.

\section{Adopt innovative intervention approaches}

Innovative approaches should be incorporated across intervention design and implementation. First, innovative intervention designs can help minimize disturbances in the factory without compromising the intervention's impact, which will increase support from the factory management. Interventions should also be designed to be flexible enough so as not to be affected by high worker turnover. Second, a one-size-fits-all approach is not appropriate for GFWs, since they are a diverse group with different characteristics and needs. Third, innovative intervention approaches could adopt multiple components/strategies. The study found that workers sought health care differently, depending on the health issues, and considered several factors when deciding whether to seek health services and when selecting a provider. To effectively promote worker health, interventions should therefore aim to address multiple barriers for workers, for example, cost, health knowledge, information about health services, distance, and quality of care. The majority of respondents noted health literacy in particular as a strategy that should be included in future health interventions to promote worker health.

\section{Pursue support from relevant government bodies}

To maximize and sustain the impacts of the interventions, support and collaboration from relevant government bodies should be pursued. Respondents interviewed from implementing NGOs noted that working with local and national government bodies promoted greater cooperation among all stakeholders. Public health facilities also played a very important role in providing high-level health services, as illustrated in workers' health-seeking pathways. With the early implementation of NSSF health insurance scheme, coordination between implementing organizations and relevant government bodies from the Ministry of Labour and Vocational Training and the Ministry of Health could promote the exchange of knowledge, gained from NGOs' implementation of health interventions, on how to build responsive, sound policies to better promote worker health. 


\section{REFERENCES}

Heng, Molyaneth and Ashish Bajracharya. 2017. "Garment Sector Health Interventions in Cambodia: A Comprehensive Review," Research Report. Phnom Penh, Cambodia: Population Council, The Evidence Project.
Yat, Bunmey, Carolyn Rodehau, and David Wofford. 2017. “Workplace Health and the Garment Sector in Cambodia," Policy Brief. Washington, D.C. and Phnom Penh, Cambodia: Population Council, The Evidence Project.
THE EVIDENCE PROJECT

Population Council \#12 Eo, St. 41, Sangkat Tonle

Bassac

Khan Chamkar Morn Phnom Penh, Cambodia

+85510330184

evidenceproject@popcouncil.org

\section{CONTRIBUTORS}

Molyaneth Heng Population Council

Ashish Bajracharya Population Council

Chhorvann Chhea National Institute of Public Health

Bandeth Ros National Institute of Public Health

Sopheab Heng National Institute of Public Health

Hyunwoo June Choo Harvard T.H. Chan School of Public Health

Karen Hardee Population Council Kate Gilles Population Reference Bureau

Anneka Van Scoyoc Population Reference Bureau

( USAID

The Evidence Project is made possible by the generous support of the American people through the United States Agency for International Development (USAID) under the terms of cooperative agreement no. AID-OAA-A-13-00087. The contents of this document are the sole responsibility of the Evidence Project and Population Council and do not necessarily reflect the views of USAID or the United States Government.

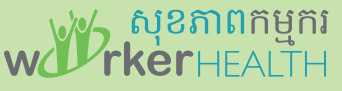
Family Planning and Health Organizations 2: Sustainable Networks (SIFPO2) program, which is funded by the US Agency for International Development (USAID), under Cooperative Agreement No. AID-OAA-A-14-000036.

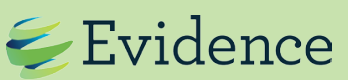

The Evidence Project uses implementation science-the strategic generation, translation, and use of evidence-to strengthen and scale up family planning and reproductive health programs to reduce unintended pregnancies worldwide. The Evidence Project is led by the Population Council in partnership with INDEPTH Network, International Planned Parenthood Federation, PATH, Population Reference Bureau, and a University Research Network.

Suggested Citation: Heng, Molyaneth, Ashish Bajracharya, Chhorvann Chhea, Bandeth Ros, Sopheab Heng, and Hyunwoo June Choo. 2017. "Health Needs, Health Seeking Pathways, and Drivers of Health Seeking Behaviors of Female Garment Factory Workers in Cambodia: Findings from a Qualitative Study in Phnom Penh and Kandal Provinces" Policy Brief. Washington DC and Phnom Penh, Cambodia: Population Council, The Evidence Project.

(C) 2017 The Population Council, Inc

Photo credit for all photos: (c) 2016 Ashish Bajracharya 